TABLE III._Clinical Suspicion of Pulmon ary Embolism. Pulmonary Perfusion Scan

\begin{tabular}{|c|c|c|c|}
\hline Scan Findings & Normal Scan & $\begin{array}{l}\text { Diffuse, Patchy, Non-segmental in } \\
\text { Distribution or Predominantly Non- } \\
\text { segmental Defects in Patients with } \\
\text { Chronic Obstructive Pulmonary Disease } \\
\text { or Bronchial Asthma }\end{array}$ & $\begin{array}{l}\text { Multiple Segmental or Subsegmental } \\
\text { Perfusion Defects with Normal Chest } \\
\text { Radiograph or with Radiographic Signs } \\
\text { known to occur in Pulmonary Embolism }\end{array}$ \\
\hline 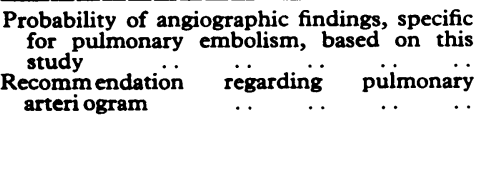 & $\begin{array}{c}\text { Very low } \\
\text { Not recommended }\end{array}$ & $\begin{array}{c}25 \% \\
\text { Recommended }\end{array}$ & $\begin{array}{l}\text { N5\% } \\
\text { Not necessary, especially in patients } \\
\text { without chronic obstructive pulmonary } \\
\text { disease, unless surgery or long-term } \\
\text { anticoagulation is contemplated }\end{array}$ \\
\hline
\end{tabular}

of segmental perfusion defects in proved cases of pulmonary embolism, we believe that any perfusion defect seen in the posterior view should be correlated with the lateral views to decide whether the defect is segmental or not. Sixteen per cent. of the patients with segmental perfusion defects had only non-specific arteriographic findings and the remaining $9 \%$ had normal arteriograms. Of the six patients in this group who had non-specific or normal arteriograms, only two had clinical evidence of chronic obstructive pulmonary disease. Probably some of the patients who did not have specific angiographic findings did in fact have pulmonary embolism. Normal or non-specific angiographic findings in proved cases of pulmonary emboli have been reported (Moser et al., 1966, Wellman et al., 1969).

In patients with chronic obstructive pulmonary disease it is unusual to find perfusion defects entirely confined to anatomical segments. These defects are usually diffuse or patchy and a superimposed embolus can never be interpreted with certainty from the scan. Diffuse or even segmental perfusion defects may occur in bronchial asthma, and pulmonary embolism can also present as asthma (Olazábal et al., 1968). Similarly, pulmonary venous hypertension secondary to congestive cardiac failure can also produce perfusion defects, usually in the bases of the lung. Thus, in patients with chronic obstructive pulmonary disease, congestive cardiac failure, or bronchial asthma only an arteriogram can establish the diagnosis. Pulmonary arteriography showed specific evidence of emboli in $25 \%$ of patients (those with "medium probability" and "low probability" scans combined) with this type of perfusion defects, while $40 \%$ had non-specific angiographic abnormalities. Non-specific angiographic abnormalities indistinguishable from pulmonary emboli occur in chronic obstructive pulmonary disease or congestive cardiac failure, thus making the angiographic interpretation also difficult. A significant number of our patients with scans grouped as "medium or low probability for pulmonary embolism" and normal or non-specific arteriograms (17 out of 21 cases) had chronic obstructive or other parenchymal disease of the lung or congestive cardiac failure.

In 12 patients the lung scans were completely normal and in none of these cases was a specific finding of emboli detected in the subsequent angiogram. We conclude that the lung scan is a simple and sensitive screening procedure for pulmonary embolism whereas the arteriogram is more specific but may be less sensitive. The diagnostic accuracy of lung scanning can be improved if (1) all the four views-anterior, posterior, and both laterals-are obtained, (2) the shape and position of the perfusion defects are anatomically localized, and (3) the scan and chest radiograph are correlated. We also recommend the diagnostic sequence shown in Table III in a patient suspected of pulmonary embolism.

Supported by U.S.P.H.S. Grant 10548.

\section{REFERENCES}

Freiman, D. G., Suyemoto, J., and Wessler, S. (1965). New England Fournal of Medicine, 272, 1278 .

Hildner, F. J., and Ormond, R. S. (1967). Fournal of the American Medical Association 202, 567.

Morrell, M. T., and Dunnill, M. S. (1968). British fournal of Surgery,

55, 347. M., Tisi, G. M., Rhodes, P. G., Landis, G. A., and Miale, A. (1966). American fournal of Cardiology, 18, 810 .

Olazábal, F., jun., Román-Irizarry, L. A., Oms, J. D., Conde, L., and Marchand, E. J. (1968). New England Fournal of Medicine, 278, 999.

Poulose. K., Reba, R. C., and Wagner, H. N., jun. (1968). New England Fournal of Medicine, 279, 1020

Soloff, L. A., and Rodman, T. (1967). American Heart fournal, 74, 710.

Stein, P. D., et al. (1967). American Heart fournal, 73, 730.

Wellman, H. N., et al. (1969), fournal of Nuclear Medicine, 10, 380

\title{
Anaemia and Surgery
}

\section{J. N. LUNN,* M.D., F.F.A. R.C.S. ; P. C. ELWOOD, † M.D.}

\begin{abstract}
Cummary: In 1,584 patients who had received an anaesthetic the association was examined between circulating haemoglobin level and the postoperative course (length of hospital stay, the occurrence of a complication, and death). In men a significant association $(P<0.05)$ was found for each index, but in women this was present only for death.
\end{abstract}

It is suggested that the hypothesis which best explains

\footnotetext{
* Senior Lecturer in Anaesthetics, Welsh National School of Medicine, Cardiff.

† Member of M.R.C. Epidemiology Research Unit, Cardiff.
}

\begin{abstract}
the associations, and is consistent with further analyses of the data, is that the preoperative haemoglobin level reflects the severity of the underlying condition which has necessitated surgery. A randomized clinical trial would test the alternative hypothesis that anaemia constitutes an additional risk in surgical procedures.
\end{abstract}

\section{Introduction}

Traditionally, anaemia is believed to increase the risk of surgery, and it is common practice for non-urgent surgery to be postponed if a patient is anaemic. The level of circulating 
haemoglobin $¥$ below which such an effect exists is, however, unknown. Nor is it known whether the risk is real. The justification for considering anaemia as a risk is based on the theoretical concept of oxygen flux (Freeman and Nunn, 1963). Clearly, the presence of anaemia increases the risk of depletiun of available oxygen. Thus some anaesthetists have hitherto tended to set an arbitrary level of haemoglobin below which they regard the risks of elective surgical anaesthesia as unjustifiable. It may be, therefore, that either surgery is occasionally postponed unnecessarily because of anaemia or that surgery is occasionally undertaken in patients who should first have had treatment for anaemia.

This report describes a study of the association between circulating haemoglobin level and postoperative progress. It was based on data which are collected routinely by the department of anaesthetics in Cardiff.

\section{Method}

The records of all patients who had received an anaesthetic in one of the teaching hospitals during the period JanuaryJune 1969 were divided into subgroups defined by sex, age, and operation. Age was grouped at four levels (25-44 years, 45-64 years, 65-74 years, and 75 years and over). Operations were classified in four groups: (1) minor superficial, (2) major superficial, (3) minor intra-abdominal (intrathoracic, intrapelvic, or intracranial), and (4) major intra-abdominal (intrathoracic, intrapelvic, or intracranial).

Patients who had had a uterine dilatation and curettage or a similar gynaecological operation were omitted. Though this group was large it was felt that the procedure for the patients' admission and early discharge, being fairly well standardized, might obscure any association which might exist between haemoglobin level and postoperative course. There are undoubtedly other operations which might have been excluded for similar reasons, but because the numbers of patients involved in such groups were relatively small, and also because of uncertainty about the admission-discharge procedure, no other exclusions were made. The distribution of preoperative haemoglobin levels is shown in Table $I$.

TABLE I.-Distribution of Preoperative Haemoglobin Levels

\begin{tabular}{c|c|c|c|c|c}
\hline $\begin{array}{c}\text { Haemoglobin } \\
(\mathrm{g} . / 100 \mathrm{ml} .)\end{array}$ & Males & Females & $\begin{array}{c}\text { Haemoglobin } \\
(\mathrm{g} . / 100 \mathrm{ml} .)\end{array}$ & Males & Females \\
\hline 4 & 2 & - & 12 & 84 & 121 \\
5 & 5 & 1 & 13 & 92 & 229 \\
6 & 4 & 9 & 14 & 191 & 177 \\
7 & 7 & - & 15 & 167 & 78 \\
8 & 17 & 10 & 16 & 107 & 17 \\
9 & 17 & 22 & 17 & 45 & 5 \\
11 & 17 & 25 & Totals & $819^{*}$ & $766^{*}$ \\
\hline
\end{tabular}

* Includes patients who died after operation and who are included in Table IV.

Haemoglobinometry is performed on many patients who are to have an anaesthetic, and the level may be entered on the anaesthetic reoord. When it had not been entered it was obtained, if possible, from the records of the haematology department. Circulating haemoglobin (in g. $/ 100 \mathrm{ml}$. blood) was grouped at four levels (under 10, 10-11.9, 12-14.9, and 15 and over). Where a patient was known to have had a blood transfusion after this estimate had been made the records were excluded.

Postoperative progress was assessed in three ways.

(1) Complication.-The decision regarding which events are recorded in the anaesthetic records as a "complication" is left to the anaesthetist. This method is unsatisfactory, depending, as it obviously does, on opinion and the degree of conscientiousness

¥ This term is used to describe the value of haemoglobin in $\mathrm{g} . / 100 \mathrm{ml}$. determined from peripheral venous blood. with which the record is completed. There are likely, therefore, to be errors in this index.

(2) The length of postoperative stay in hospital was used, grouped at four levels (less than 4 days, 4 to 6 days, 7 to 13 days, and 14 days or longer). This information is obtained by a clerk from hospital bed-state information and transferred to the anaesthetic record card.

(3) The occurrence of death following operation and before discharge was also used as an index of progress. This too is recorded by a clerk.

There are 32 subgroups defined by sex, age, and operation group. Within each of these the association between circulating haemoglobin level and postoperative progress was examined. The method of statistical analysis was as follows: within each sex and operation group, and within each of the four age groups, the observed numbers of patients in each of the 16 subgroups defined by haemoglobin level and duration of postoperative stay were compared with those expected on a null hypothesis. The null hypothesis used is that "circulating haemoglobin level has no association with the length of postoperative stay" (or the occurrence of death or a complication). Because of the small numbers in the individual cells, distributions were summed over age and operation group.

\section{Results}

There were 2,441 anaesthetic records available for the period under study. Of these, $1,233(50 \%)$ had the preoperative haemoglobin level entered. A further 351 (14\%) haemoglobin estimations were obtained by linking records in the haematology department. The associations between the occurrence of a postoperative complication and haemoglobin level are shown in Table II. The men with low haemoglobin levels had a significant excess $(P<0.05)$, but in women there is no such evidence. The associations between haemoglobin level and duration of postoperative stay are shown in Table III. There is a significant association in men, those with low haemoglobin levels tending to have longer postoperative ștays than expected. In women there is a similar trend, but the association is weak and not statistically significant.

TABLE II.-Distribution of Postoperative Complications by Haemoglobin Level. Distribution Expected on a Null Hypothesis, Shown in Parentheses: this has been Standardized for Age and Type of Operation (See
Text)

\begin{tabular}{|c|c|c|c|c|}
\hline \multirow{2}{*}{$\begin{array}{l}\text { Haemoglobin } \\
(\mathrm{g} . / 100 \mathrm{ml} .)\end{array}$} & \multicolumn{2}{|c|}{ Males } & \multicolumn{2}{|c|}{ Fernales } \\
\hline & Complication & Total & Complication & Total \\
\hline $\begin{array}{l}<10 \\
10- \\
12 \\
15+ \\
\end{array}$ & $\begin{array}{rr}7 & (3.9) \\
11 & (5.3) \\
18 & (21.0) \\
14 & (19.8) \\
\end{array}$ & $\begin{array}{r}44 \\
77 \\
359 \\
309 \\
\end{array}$ & $\begin{array}{rr}2 & (2.5) \\
10 & (7.3) \\
33 & (33.3) \\
5 & (6.9) \\
\end{array}$ & $\begin{array}{r}34 \\
91 \\
522 \\
96 \\
\end{array}$ \\
\hline \multirow[t]{2}{*}{ Total } & 50 & 789 & 50 & 743 \\
\hline & \multicolumn{2}{|c|}{$\begin{array}{c}x^{2}=11.42 ; \text { D.F }=2 \\
0.01>P>0.001\end{array}$} & \multicolumn{2}{|c|}{$\begin{array}{c}x^{2}=0.65 ; \text { D.F. }=2 \\
0.80>P>0.70\end{array}$} \\
\hline
\end{tabular}

TABLE III.-Distribution of Patients by Preoperative Haemoglobin Level and Duration of Postoperative Stay in Hospital. Distribution wevel and Duration of Postoperative Stay in Hospital. Distribution
which would be Expected on a Null Hypothesis is Shown in Parentheses

\begin{tabular}{|c|c|c|c|c|c|c|c|c|c|}
\hline \multirow{2}{*}{$\begin{array}{c}\text { Haemo- } \\
\text { globin } \\
\text { (g. } / 100 \mathrm{ml} .)\end{array}$} & \multicolumn{9}{|c|}{ Duration of Stay (Days) } \\
\hline & & $<4$ & & $1-6$ & & $7-13$ & & $14+$ & Total \\
\hline $\begin{array}{l}<10 \\
10- \\
12- \\
15+\end{array}$ & $\begin{array}{r}10 \\
19 \\
151 \\
121\end{array}$ & $\begin{array}{r}(14.2) \\
(27 \cdot 6) \\
(141 \cdot 8) \\
(117 \cdot 9)\end{array}$ & $\begin{array}{r}6 \\
7 \\
65 \\
53\end{array}$ & $\begin{array}{c}\text { Male } \\
(6 \cdot 9) \\
(12 \cdot 4) \\
(58 \cdot 8) \\
(52 \cdot 8)\end{array}$ & $\begin{array}{r}4 \\
24 \\
84 \\
84\end{array}$ & $\begin{array}{l}(10 \cdot 2) \\
(19 \cdot 4) \\
(88 \cdot 8) \\
(76 \cdot 9)\end{array}$ & $\begin{array}{l}24 \\
27 \\
59 \\
51\end{array}$ & $\begin{array}{l}(12 \cdot 0) \\
(17 \cdot 7) \\
(70 \cdot 0) \\
(62 \cdot 4)\end{array}$ & $\begin{array}{r}44 \\
77 \\
359 \\
309\end{array}$ \\
\hline Total & 301 & & 131 & & 196 & & 161 & & 789 \\
\hline $\begin{array}{l}10 \\
10 \\
12- \\
15+\end{array}$ & $\begin{array}{r}7 \\
19 \\
163 \\
36\end{array}$ & $\begin{array}{r}(8.9) \\
(23.1) \\
(164.4) \\
(28.7)\end{array}$ & $\begin{array}{l}2 \\
11 \\
81 \\
18\end{array}$ & $\begin{array}{c}\text { Femal } \\
(5 \cdot 0) \\
(12 \cdot 2) \\
(77 \cdot 7) \\
(17 \cdot 1)\end{array}$ & $\begin{array}{r}9 \\
32 \\
166 \\
23\end{array}$ & $\begin{array}{r}(10.7) \\
(28.6) \\
(160.3) \\
(30.5)\end{array}$ & $\begin{array}{r}16 \\
29 \\
112 \\
19\end{array}$ & $\begin{array}{r}(8.9) \\
(27.1) \\
(119.7) \\
(20.3)\end{array}$ & $\begin{array}{r}34 \\
91 \\
522 \\
96\end{array}$ \\
\hline Total & 225 & & 112 & & 230 & & 176 & & 743 \\
\hline
\end{tabular}

Males: $x^{2}=34 \cdot 0 ;$ D.F. $=9 ; P<0.005$. Females : $x^{2}=14 \cdot 1 ;$ D.F. $=9 ; 0 \cdot 20>P>0 \cdot 10$. 
In both sexes there is a significant association between the number of deaths during the postoperative period in hospital and the preoperative haemoglobin level (Table IV). In both sexes the number of deaths was greater than expected in anaemic patients.

TABLE IV.-Distribution of Postoperative Deaths by Haemoglobin Level. Distribution Expected on a Null Hypothesis Shown in Parentheses

\begin{tabular}{|c|c|c|c|c|}
\hline \multirow{2}{*}{$\begin{array}{c}\text { Haemoglobin } \\
\text { Level }\end{array}$} & \multicolumn{2}{|c|}{ Males } & \multicolumn{2}{|c|}{ Females } \\
\hline & Deaths & \multirow{2}{*}{$\begin{array}{c}\text { Totals } \\
52 \\
81 \\
367 \\
319\end{array}$} & Deaths & \multirow{2}{*}{$\begin{array}{c}\text { Totals } \\
42 \\
97 \\
527 \\
100\end{array}$} \\
\hline $\begin{array}{l}<10 \\
10- \\
12- \\
15+\end{array}$ & $\begin{array}{rr}8 & (1 \cdot 8) \\
4 & (3 \cdot 5) \\
8 & (14 \cdot 3) \\
10 & (10 \cdot 4)\end{array}$ & & $\begin{array}{lr}8 & (1.5) \\
6 & (3.5) \\
5 & (14.5) \\
4 & (3.6)\end{array}$ & \\
\hline \multirow[t]{2}{*}{ Total } & 30 & 819 & 23 & 766 \\
\hline & \multicolumn{2}{|c|}{$\begin{array}{c}x^{2}=12.43 ; \underset{D}{D} . F_{.}=2 \\
0.01>P>0.001\end{array}$} & \multicolumn{2}{|c|}{$x^{2}=21 \cdot 32 ; \underset{P}{2}<0 . F .=1$} \\
\hline
\end{tabular}

\section{Discussion}

This study suggests that a preoperative low haemoglobin level is associated with an excess risk in surgical procedures in men in terms of each of the three indices used. In women the study gives no evidence of a significant association between haemoglobin level and postoperative stay or the occurrence of a complication, but the number of deaths during the postoperative period show a significant association with preoperative haemoglobin level. The existence of these associations does not necessarily establish unequivocally that anaemia constitutes an additional risk in surgery. This is a possible explanation of the results, but the lack of consistency in the data makes the consideration of several alternative hypotheses advisable.

There are several possible sources of bias in these data. A few anaesthetic records were not available, but their omission is probably not serious, as they do not appear to have been selected by severity of condition, by age, or by any other relevant factor. Furthermore, no estimation of haemoglobin is available for over one-third of the patients. Again the omissions are unlikely to be serious, as most of these patients appear to have had simple operations necessitating a relatively short postoperative stay, and they had, on the whole, a low incidence of complications and death. A further source of bias occurred because of blood transfusions given at some time after the preoperative estimation of haemoglobin level. The records of patients in whom this is known to have occurred were withdrawn, but there may have been others. Nevertheless, if anaemia matters and if there is, as is commonly believed, an associated depletion in iron-containing tissue enzymes, then the ability of the tissues to withstand trauma, and the whole body to withstand hypoxia, is likely to be impaired by a low level of circulating haemoglobin. A blood transfusion very shortly before or after operation is not likely to remove this effect completely.

In view of the discrepancy between the trends shown by the data for men and those for women, possibly a low haemoglobin level in a patient may simply indicate an underlying condition of greater severity than in a patient with a normal haemoglobin level. The data suggest that if this is true, then the effect is pronounced in men. In women, on the other hand, menstrual iron loss has a most disturbing effect on iron balance (Elwood, Rees, and Thomas, 1968) and anaemia is common. A relation between the severity of the conditions requiring surgery and the level of circulating haemoglobin may therefore be obscured to some extent in women. Some aspects of the distributions of haemoglobin levels in the subjects of this study are consistent with that explanation. The distribution in women (Table I) is not very different from that obtained in epidemiological studies of representative community samples, while the men show much greater negative skewness than is found in representative community samples. This increased proportion of low values in men, but not in women, suggests that iron balance has been seriously disturbed in many men admitted for operation. Probably in many cases the condition for which surgery is required has caused the anaemia.

Study of the possible association between the severity of the conditions requiring surgery and the haemoglobin level is not easy with these data. We have, however, examined two aspects. The "surgical diagnoses" of the patients with a preoperative haemoglobin level of less than $10 \mathrm{~g}$. were listed. Thirty-nine $(75 \%)$ men and $21(50 \%)$ women were judged to have a serious condition which is likely to have led to anaemia (kidney disease, malignant tumours, etc.). The proportion of subjects in whom surgery was undertaken as an emergency shows a pronounced gradient from the most anaemic patients to those with normal haemoglobin levels $(33 \%, 32 \%, 17 \%$, and $18 \%$ in men; $34 \%, 13 \%, 16 \%$, and $14 \%$ in women).

The evidence, on the whole, suggests that the relation between haemoglobin level and postoperative progress is not causal. Yet if it were it would seem beneficial to patients with anaemia to delay surgery until this had been treated, provided that such a delay was not prejudicial on other clinical grounds. Valid evidence on this point, however, will be obtained only from a clinical trial in which anaemic patients, preferably male, in whom a delay before surgery is not unreasonable, are allotted at random either to a group in which the anaemia is treated before surgery or to a group which is not treated in this way. In view of the uncertainty in our conclusions, a randomized trial of this kind might be justifiable, provided severely anaemic patients were excluded.

We wish to thank the following for their co-operation: Professor W. W. Mushin, professor of anaesthetics, Professor A. L. Jacobs, professor of haematology, and Mr. R. E. Henson, chief records officer of the department of pathology, all of the Welsh National School of Medicine. Finally we would like to thank the department of anaesthetics because without their unique record system this study could never have been made.

REFERENCES Elwood, P. C., Rees, G., and Thomas, J. D. R. (1968). British foumal
of Social and Preventive Medicine, 22, 127. Freeman, J., and Nunn, J. F. (1963). Clinical Science, 24, 135. 